\section{Unusual presentations of neurological conditions: make your diagnoses}

M D O'Brien

J R Soc Med 2005;98:569.569-570

\section{QUESTION 1}

A man of 67 had had his self-winding Rolex watch for many years without any problems, but it then kept stopping and he had to manually rewind it. Thinking that it needed cleaning, he took it to be repaired, but when he got back it stopped again after a few days. He was subsequently told that there was nothing wrong with the watch. This was the first sign of this patient's condition at the time that he was otherwise asymptomatic. What was the diagnosis?

\section{QUESTION 2}

A 52-year-old man had lost one eye from trauma 15 years earlier and had a glass eye, which he wore with no problem over the years. He then found that he could not retain the glass eye which kept falling out, he was otherwise asymptomatic. What was the diagnosis?

\section{QUESTION 3}

A woman aged 25 had just got married and was on her honeymoon on a tropical island. She was sunbathing topless when her husband suggested that they go for an ice cream. She pulled on a T-shirt and they walked along the beach. She became aware that the friction from the T-shirt had caused nipple erection on the right but not on the left; it was the asymmetry which concerned her. Her left breast

Emeritus Physician, Department of Neurology, Guy's Hospital, London SE1 9RT, UK

E-mail: obrmd@btinternet.com felt normal to touch. This was the first sign of her condition and she was otherwise asymptomatic at the time. What was the diagnosis?

\section{QUESTION 4}

A woman of 32 had a 3 -year-old son and had just delivered her second child after a long labour with assisted delivery. After delivery she had some hesitancy and urgency of micturition and 2 months later when she resumed normal sexual activity, she failed to achieve orgasm. This surprised and upset her, because she had previously enjoyed a vigorous sex life. At first she and her GP were happy to ascribe this to her recent delivery and at the time she was otherwise asymptomatic. What was the diagnosis?

\section{QUESTION 5}

A woman aged 42 complained of sudden severe sharp pain in the sole of the foot extending forward to the toes with penetrative vaginal intercourse. This was the first sign of her condition - at the time she was otherwise asymptomatic. What was the diagnosis?

\section{QUESTION 6}

A 16-year-old girl had been referred to a psychiatrist with the possible diagnosis of an eating disorder, because she refused to finish her meals, claiming that she was unable to do so. What was the diagnosis?

\section{QUESTION 7}

A newly married man of 28 was brought a cup of tea in bed by his wife, but when he gripped the handle the cup rotated spilling tea over the bed. There were no sensory symptoms. What was the diagnosis?

See next page for the correct diagnoses.

Acknowledgments I am grateful to the late Dr I C K MacKenzie for the first two patients and to Dr W A C McAllister, who drew my attention to patient No. 5. 


\section{ANSWER TO QUESTION 1}

Left hemibradykinetic Parkinson's disease without tremor. The relative immobility of his left arm and hand, with failure to swing the arm when walking, did not activate the self-winding mechanism.

\section{ANSWER TO QUESTION 2}

Dysthyroid ophthalmoplegia or Grave's disease, which often presents with double vision, but that was not possible in this patient with only one eye. The proptosis which occurs in this condition is due to swelling of retro-orbital tissue, particularly the ocular muscles; which pushed out his glass eye.

\section{ANSWER TO QUESTION 3}

Syringomyelia. Examination showed left cape distribution dissociated sensory impairment between $\mathrm{C} 4$ and T7 with depressed reflexes in the left arm. MRI showed a cervical syrinx. There was no evidence of tonsillar herniation or any other abnormality at the cranio-cervical junction. The central spinal cord cavitation which occurs in syringomyelia first affects the decussating pain and temperature fibres destined for the anterior-lateral spinothalamic tract and the reflex arc. The posterior columns (light touch and joint position sense) are not affected in the early stages. Nipple erection must be partly dependent on spinothalamic function and this presumably explains the use of ice-cubes by topless models.

\section{ANSWER TO QUESTION 4}

Multiple sclerosis. When first seen about 6 months later she had developed some unsteadiness of gait. Examination showed a mild spastic paraparesis with strongly extensor plantar responses. Bladder symptoms may be the first sign of multiple sclerosis.

\section{ANSWER TO QUESTION 5}

Presacral plexiform neurofibroma. Pressure on the neuroma during intercourse must have irritated the first sacral root (S1) causing pain in S1 distribution.

\section{ANSWER TO QUESTION 6}

Myasthenia gravis. She subsequently developed difficulty in swallowing and double vision. Muscle fatigue is characteristic of myasthenia and quite commonly occurs while chewing with other signs of facial and bulbar involvement, but it is rare as an initial complaint.

\section{ANSWER TO QUESTION 7}

Anterior interosseous nerve palsy. The AIN supplies pronator quadratus, flexor pollicis longus and flexor digitorum profundus to the index and middle fingers; it has no sensory component. Weakness of pronator quadratus is virtually asymptomatic, but weakness of the long flexors to the thumb and index finger affects pinch grip and therefore causes difficulty in writing and holding a cup by its handle. In this patient it was probably caused by his wife sleeping on his outstreched arm, compressing the nerve in the forearm; a form of honeymoon palsy. 